\title{
Numerical Study on the Behavior of Square Stiffened Caissons Penetrating into Normally Consolidated Clay
}

\author{
Wei Liu $\mathbb{D}^{1},{ }^{1}$ Zhihuai Huang $\mathbb{D}^{2}{ }^{2}$ and Mi Zhou $\mathbb{D}^{3}$ \\ ${ }^{1}$ Guangzhou Urban Planning \& Design Survey Research Institute, \\ Guangdong Enterprise Key Laboratory for Urban Sensing, Monitoring and Early Warning, Guangzhou 510060, China \\ ${ }^{2}$ Key Laboratory of the Pearl River Estuary Regulation and Protection of Ministry of Water Resources, \\ Pearl River Water Resources Research Institute, 80 Tianshou Rd., Guangzhou 510611, China \\ ${ }^{3}$ School of Civil and Transportation Engineering, South China University of Technology, 381 Wushan Road, \\ Guangzhou 510640, China
}

Correspondence should be addressed to Mi Zhou; zhoumi@scut.edu.cn

Received 5 July 2021; Accepted 13 August 2021; Published 31 August 2021

Academic Editor: Xihong Zhang

Copyright $\odot 2021$ Wei Liu et al. This is an open access article distributed under the Creative Commons Attribution License, which permits unrestricted use, distribution, and reproduction in any medium, provided the original work is properly cited.

\begin{abstract}
Significant difference between predicted and measured installation resistance of stiffened suction caissons was identified due to the existing uncertainty regarding the mobilized soil flow mechanisms. This paper describes an extensive investigation of square stiffened caisson penetration in nonhomogeneous clays undertaken through large deformation FE (LDFE) analysis to identify the soil flow mechanisms around and between lateral ring stiffeners. A detailed parametric study has been carried out, exploring a range of nondimensional parameters related to stiffened caisson geometry, caisson roughness, and soil strength. The LDFE results were compared with centrifuge test data in terms of soil flow mechanisms, with good agreement obtained. Two interesting features of soil flow inside the caisson were observed including soil backflow into the gaps between the embedded stiffeners and soil heaving at the surface. It shows that the cavity depth can reach $\sim 5 \mathrm{~m}$. Finally, simple expressions were proposed for estimating the critical depths of soil backflow and cavity formation.
\end{abstract}

\section{Introduction}

To avoid the buckling failure of the thin wall of a long caisson during installation, the skirt is strengthened with internal stiffeners, horizontal rings, and/or vertical flanges (see Figure 1), together with local thickening of the wall in the vicinity of the loading point. The addition of these stiffeners has created significant uncertainties regarding the soil flow mechanisms, side friction, and end bearing and consequently in the prediction of underpressure required for installation [1].

The uncertainties have been shown by the significant differences observed between the predicted caisson resistance, based on the presumed soil flow mechanisms (see Figure 2), and the measured resistance in the field. The field measurements include the stiffened caisson installation at the Laminaria field in the Timor Sea and at the Girassol field, offshore West Africa [2-4], with a detailed discussion reported by Hossain et al. [5]. Andersen et al. [1] discussed the predictions for two different hypothetical installation cases and six case histories of caissons with stiffeners carried out by four predictors using their normal design method. The predictors produced significantly different results largely due to the assumption of different soil flow mechanisms around and between the stiffeners [1].

Large deformation FE analyses and centrifuge model tests on unstiffened caisson installation were carried out by Andersen et al. [6], Zhou and Randolph [7], Chen and Randolph [8], and Westgate et al. [9], among others. They noticed no discernible difference in the axial capacity between jacked and suction-installed caisson, except Zhou and Randolph [7]. Significant proportion of soil flow was reported to occur inward into the caisson, with little outward flow. 


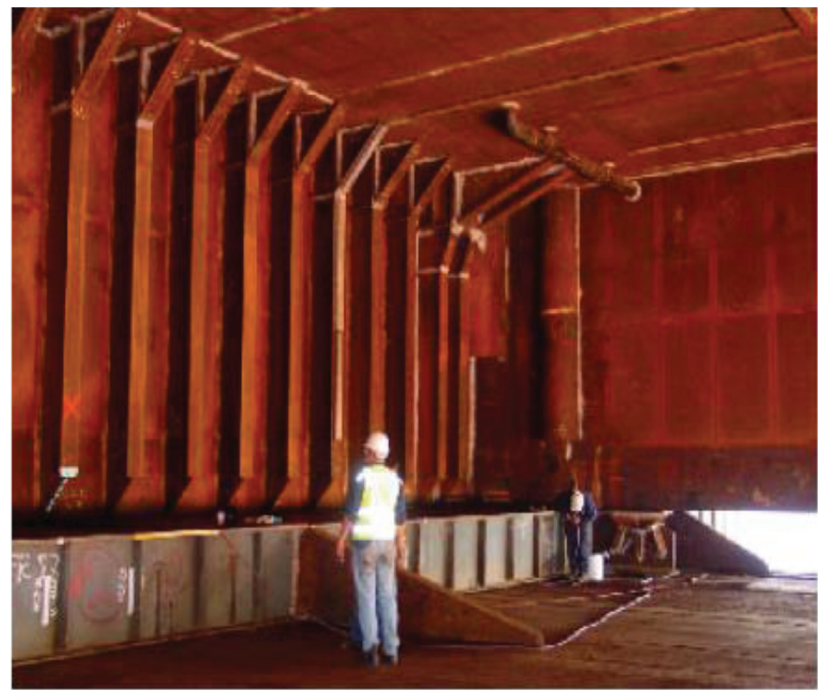

Figure 1: Photo of square stiffened caisson.

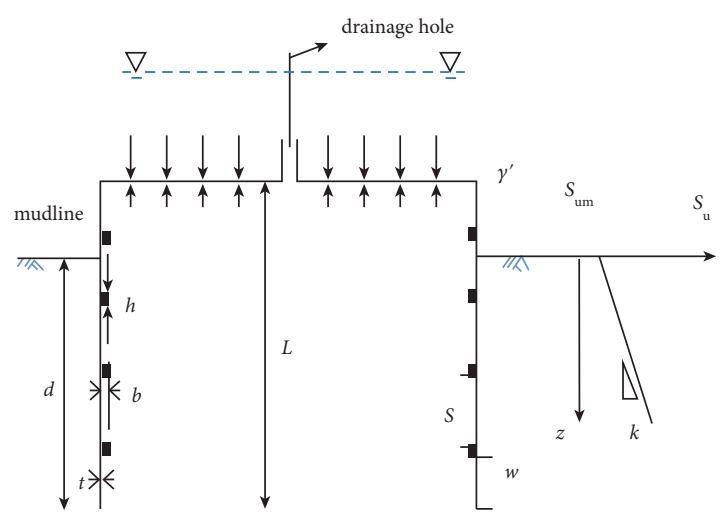

FIGURE 2: Geometry of square stiffened caisson.

This paper reports the results from an extensive investigation carried out through large deformation FE (LDFE) analysis in an attempt to provide insight into the failure mechanism of square stiffened caisson penetration in nonhomogeneous clays. Expressions are developed to estimate the critical depths of soil backflow into the gaps between the embedded stiffeners.

\section{Large Deformation Finite Element Analysis}

2.1. The RITSS Method. Randolph and $\mathrm{Hu}$ proposed a finite element method with small strain calculation based on the remeshing technique for large deformation of solid in 1998. This large deformation finite element method belongs to the arbitrary Lagrangian-Eulerian (ALE) finite element methods can be employed coupling with ABAQUS and AFNEA. This method includes the following main steps: (i) generate an initial mesh consisting of six-node triangular elements with three internal Gauss points; (ii) use the program to perform an specified increment of small strain analysis; (iii) regenerate and optimize the mesh to generate new units and nodes; (iv) interpolate the material stress and properties; and (v) check whether the displacement meets the requirements; if not, open a new finite element small deformation project and repeat the above steps until it can meet the requirements; then, close the project. The RITSS method has the significant advantage that the mesh will be constantly updated to ensure accuracy and quality, making the calculation process smooth when the project is running.

2.2. Numerical Model and Parameter Setup. A square stiffened caisson penetrating into normally consolidated clay with shear strength of $S_{\mathrm{u}}=S_{\mathrm{um}}+k z$ was analyzed in this study, with geometry of square stiffened caisson shown in Figure 2. The friction coefficient of structure-soil interfaces is $\alpha$; therefore, the limiting shear force along the interface of structure and soil is $\alpha S_{\mathrm{u}}$. All the floating bulk densities of the clay are set as $\gamma^{\prime}=6 \mathrm{kN} / \mathrm{m}^{3}$.

Because the width of squared caisson is significantly larger than the sum of the width of stiffener and thickness of skirt, the plane strain model was used to simulate the failure mechanism behavior of the squared caisson piling process. In order to prevent the boundary effects, the model was arranged in the middle of the computational mesh, and the length and width of the plane strain model were set to be $5 \mathrm{~L}$. Hinge constraints were applied along the base, while roller constraints were set at the vertical sides of the soil model. The six-node triangular mesh with three internal Gauss points was employed in this study, and nodal joint elements were used to simulate the interaction of structure and soil, where the limiting shear force is $\alpha S_{\mathrm{u}} . A$. The initial finite element mesh of the numerical model is shown in Figure 3(a). The initial penetration depth is $0.02 \mathrm{~m}$. The calculation parameters selected are shown in Table 1.

In this study, the Mohr-Coulomb constitutive model is used to simulate the clay with very low permeability, and the Tresca yield criterion is also used. Poisson's ratio $v=0.49$, friction and dilation angles $\phi=\psi=0$, and a uniform stiffness ratio $E / s_{\mathrm{u}}=500$ which is a common value for clay, where $E$ is Young's modulus. The normally consolidated clay with undrained shear strength of $S_{\mathrm{u}}=S_{\mathrm{um}}+k z\left(S_{\mathrm{um}}\right.$ is the shear 

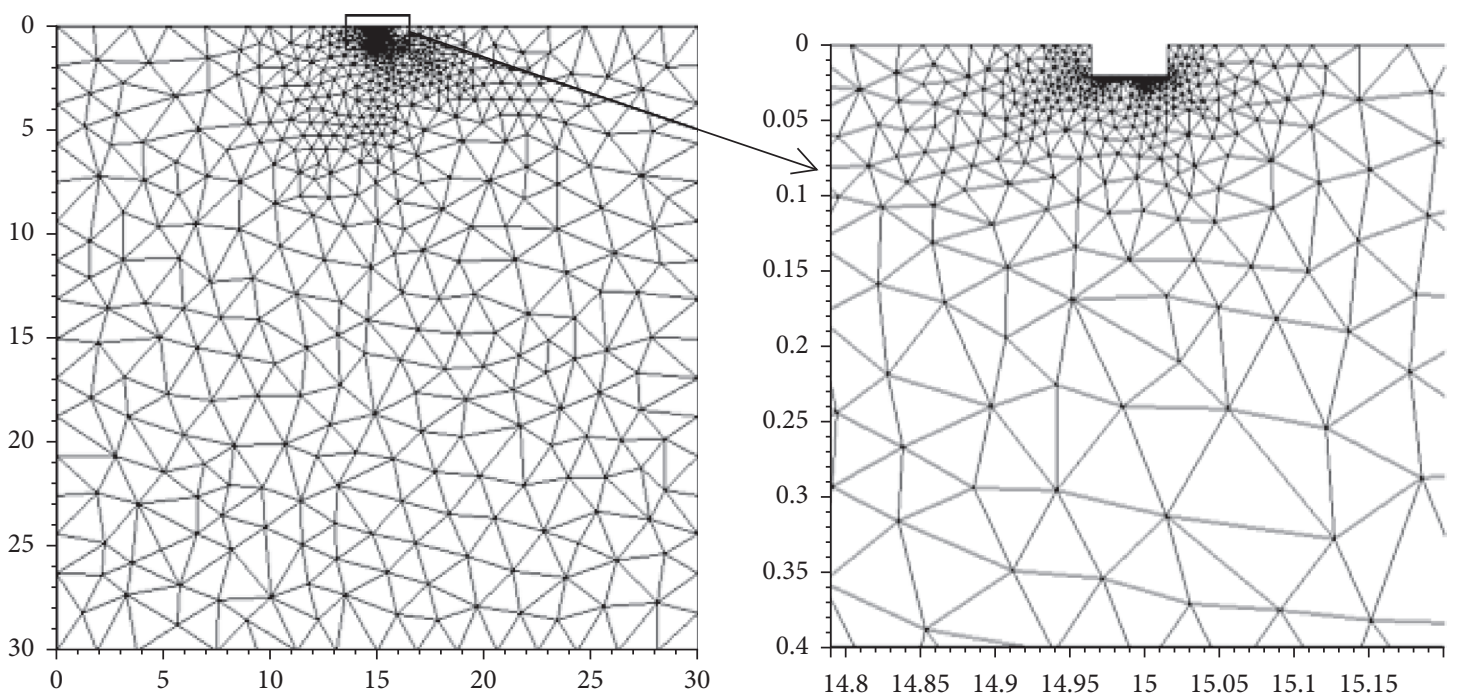

(a)

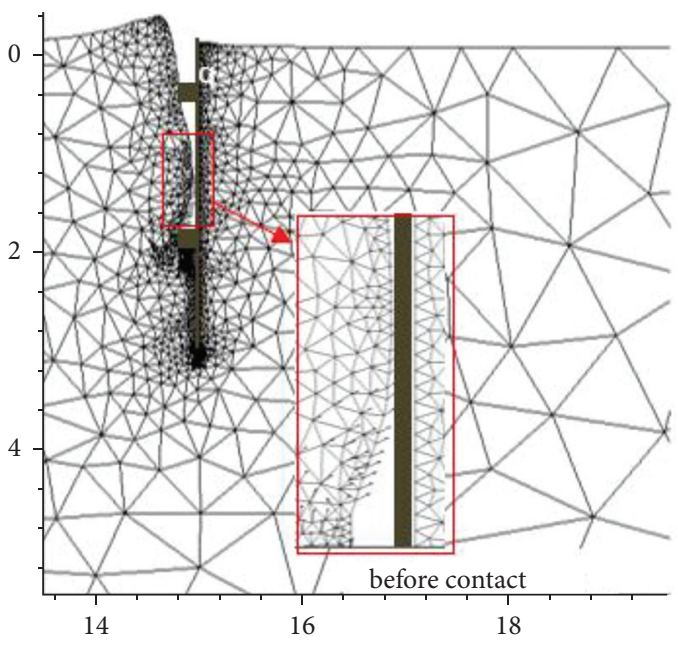

(b)

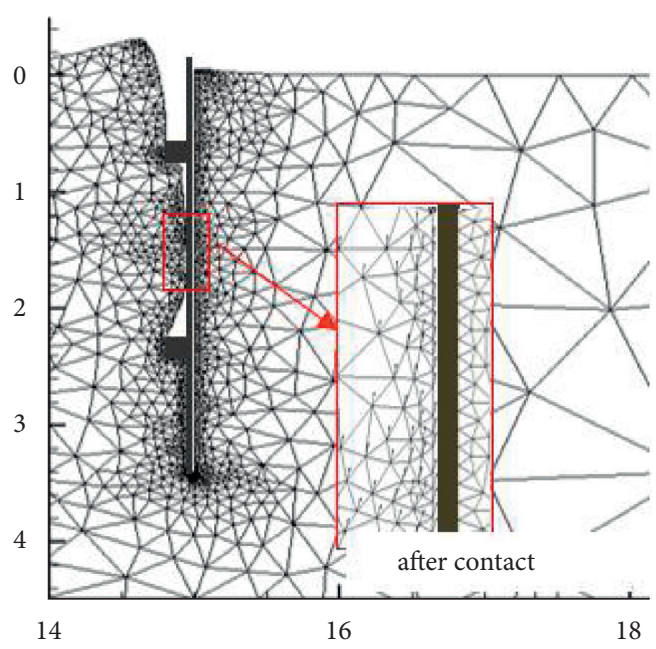

(c)

FIgUre 3: Mesh of RITSS code. (a) The initial mesh of LDFE/RITSS. (b) Dynamic mesh demonstration. (c) Established contact mesh.

TABLE 1: Summary of LDFE analyses.

\begin{tabular}{|c|c|c|c|c|c|c|c|}
\hline Analysis & $s / h$ & $b / t$ & $w / b$ & $\alpha$ & $S_{\mathrm{um}} /\left(\gamma^{\prime}(b+t)\right)$ & $(k(b+t)) / S_{\mathrm{um}}$ & Notes \\
\hline $\begin{array}{l}\text { Group 1- } \\
\text { A }\end{array}$ & 11.0 & 4.0 & 8.33 & 0.2 & ${ }^{*} 0.48$ & ${ }^{\#} 0.45$ & $\begin{array}{c}\text { Numerical model validation } \\
\text { model }\end{array}$ \\
\hline $\begin{array}{l}\text { Group 1- } \\
\text { B }\end{array}$ & 2.0 & $2.0,4.0$ & $5.3,2.7$ & 0.03 & - & - & $\begin{array}{c}\text { Numerical model validation } \\
\text { model }\end{array}$ \\
\hline Group 2 & 10.0 & 3.0 & 6.7 & 0.2 & 4.2 & 0.04 & Typical failure mechanism \\
\hline Group 3 & 10.0 & $\begin{array}{c}2.0 \\
3.0,5.0\end{array}$ & $\begin{array}{c}4.0,6.7 \\
10.0\end{array}$ & 0.2 & $5.6,4.2,2.8$ & $0.03,0.04,0.06$ & Effect of $b$ \\
\hline Group 4 & 10.0 & 3.0 & 6.7 & $\begin{array}{c}0.1 \\
0.2,0.4\end{array}$ & 4.2 & 0.04 & Effect of $\alpha$ \\
\hline Group 5 & $\begin{array}{l}6.0,10.0 \\
15.0\end{array}$ & 3.0 & 6.7 & 0.2 & 4.2 & 0.04 & Effect of $h$ \\
\hline Group 6 & $\begin{array}{l}6.7,10.0 \\
13.3\end{array}$ & 3.0 & 6.7 & 0.2 & 4.2 & 0.04 & Effect of $s$ \\
\hline Group 7 & 10.0 & 3.0 & 6.7 & 0.2 & $0.42,4.2,8.3$ & $0.24,0.4,0.8$ & Effect of $S_{\mathrm{u}}$ \\
\hline
\end{tabular}


TABle 1: Continued.

\begin{tabular}{|c|c|c|c|c|c|c|c|}
\hline Analysis & $s / h$ & $b / t$ & $w / b$ & $\alpha$ & $S_{\mathrm{um}} /\left(\gamma^{\prime}(b+t)\right)$ & $(k(b+t)) / S_{\mathrm{um}}$ & Notes \\
\hline Group 8 & & $\begin{array}{c}2.0 \\
3.0,5.0\end{array}$ & $\begin{array}{c}4.0,6.7 \\
10.0\end{array}$ & 0.2 & $\begin{array}{c}0.28,0.42,0.56,1.4,1.42,1.76,2.48,2.7 \\
2.93,3.53,3.6,4.2,4.68,6.25,6.67,7.56 \\
8.3,8.61\end{array}$ & - & $\begin{array}{l}\text { Cases for preparing formula } \\
(3 \times 3 \times 14=126 \text { cases })\end{array}$ \\
\hline
\end{tabular}

${ }^{*} S_{\mathrm{um}} / \gamma^{\prime} D=0.48 ;{ }^{*} k D / S_{\mathrm{um}}=0.45$ ( $D$ is the caisson diameter).

strength at mudline ranging from 0.5 to $10 \mathrm{kPa}, k$ is the gradient of shear strength ranging from 0.6 to $2 \mathrm{kPa} / \mathrm{m}$, and $z$ is the depth below mudline) is considered in this study. The lateral stress coefficient $K_{0}=1-\sin (\phi)=1$.

2.3. Validation of FE Model. Bucket foundation with horizontal stiffeners was studied through centrifuge test with $120 \mathrm{~g}$, reported by Randolph et al. [10]. The soil profile is $S_{\mathrm{u}}=15+1.25 z \mathrm{kPa}$, and the dimensional parameters of the structure are $b / t=4, s / h=11$, and $w / b=8.33$. The project of Group 1-A in Table 1 was executed. The friction coefficient $\alpha=0.2$ was used in the numerical model, and the normalized penetration resistance $P / A_{\text {base }}$ is shown in Figure 4 . It can be seen that both the trends and value of the resistance profile show a good agreement with those of the centrifuge test data.

A squared caisson penetrating in the homogeneous clay with aims of exploring the soil flow mechanism was conducted by a centrifuge model test $(25 \mathrm{~g})$, reported by Hossain et al. [5]. The test data of the centrifuge are shown in the left part of Figure 5. Group 1-B project in Table 1 was executed for the comparison, in which the related parameters of the homogeneous clay were $S_{\mathrm{u}}=12 \mathrm{kPa}$ and $\gamma^{\prime}=7.25 \mathrm{KN} / \mathrm{m}^{3}$ and the geometric parameters were $s / h=2.0, b / t=2.0$ and $4.0, w / b=5.3$ and 2.7 , and $\alpha=0.3$, respectively; the results from numerical simulation are shown in the right part of Figure 5. The results from numerical simulation and centrifuge tests were in good agreement in terms of failure mechanism, soil heave, and cavities' locations and shapes. It can be found that gaps exist between stiffeners.

\section{Results and Discussion}

3.1. Effect of Geometric Dimensions. To identify the soil failure mechanisms of square stiffened caisson installation, a typical case was executed (Group 2 in Table 1) for the case with $S_{\mathrm{u}}=5+1 z \mathrm{kPa}$. As shown in Figure 6, the inside and outside soils move upward in the initial penetration. However, with deeper penetration depth, the inside soil starts to flow rotationally and gradually fill the gap between $1^{\text {st }}$ and $2^{\text {nd }}$ row stiffeners. $H_{\mathrm{r}}$ is defined as critical rotational depth, above which soil cannot stand and can rotationally flow into the gaps between stiffeners, and $H_{\mathrm{c}}$ is defined as the limiting cavity depth.

\subsection{Effect of Stiffener Width and Interface Friction Coefficient.}

To identify the influence of the stiffener width on the behavior of squared caisson penetration, cases (Group 3 in Table 1) with various stiffener widths are carried out. Figures $7(\mathrm{a})-7(\mathrm{c})$ show the failure mechanism of the cases with $b / t=2.0,3.0$, and 5.0. It can be found that the inside soil heave height increases with stiffener width increasing. It indicate that, through analysis the data shown in those figures, the inside soil heave height increase the velocity of the soil move to the gap between the stiffeners.

For the cases with various roughness between structure and soil, similar findings are plotted in Figure 6(b), that proves that insignificant effect is induced by the interface friction coefficient has for the soil flow characteristic.

3.3. Effect of Stiffener Height and Stiffener Spacing. To check the influence of stiffener geometry, including spacing and stiffener height, on the soil failure mechanism, cases with various stiffener height and spacing are conducted (two groups (5 and 6) in Table 1). It can be seen that the inside soil stands vertically with piling depth $d / t=72$ (see Figure 8(a)), and large gaps formed between soil wall sand skirt. However, with deeper penetration $(d / t=102$, as shown in Figure $8(b))$, inside soil starts to move to fill the gaps gradually. Compared with those cases with different stiffener heights and spacings, it is found that the height and spacing of stiffener have insignificant influence on the soil movement. Hence, both stiffener height and stiffener spacing have minimal effect on $H_{r}$.

3.4. Effect of Soil Strength. Figure 9 shows the soil flow patterns for the cases with various soil strengths (Group 7 in Table 1). It can be drawn that a cavity was found between $2^{\text {nd }}$ and $3^{\text {rd }}$ row stiffeners, which is because the soil has enough strength to prevent the soil collapsing. Hence, a cavity can exist through the installation process. It is also found that the case with stiff soil is more easy for soil to stand. A similar finding for T-bar penetrometer was reported that earlier soil backflow is induced for the case of soft soil; and on the contrary, the soil harder to flow back for the case of stiff clay [11]. Therefore, it can confirm that the soil strength has significant effect on the behavior of soil flow inside the square stiffened caisson. Compared with the results with different $k$, it can also be proven that soil strength gradient $k$ has minimal influence on the behavior of soil movement.

The soil strength will affect the soil flow mechanisms; similarly, the soil disturbance will also affect soil strength around driving pile. In this paper, it is found that there existed a large soil disturbance around the caisson in the process of square stiffened caisson penetrating into normally consolidated clay (see Figure 10). The soil disturbance outside the caisson is relatively small, while the stiffeners inside the caisson cause greater disturbance to the inner soil. The disturbance will not only affect the caisson working performance but also reduce the foundation bearing capacity. Figure 9 shows a typical square stiffened caisson penetrating into the normally consolidated clay with undrained shear strength $S_{\mathrm{u}}=0.5+1 z(\mathrm{kPa})$; in the 


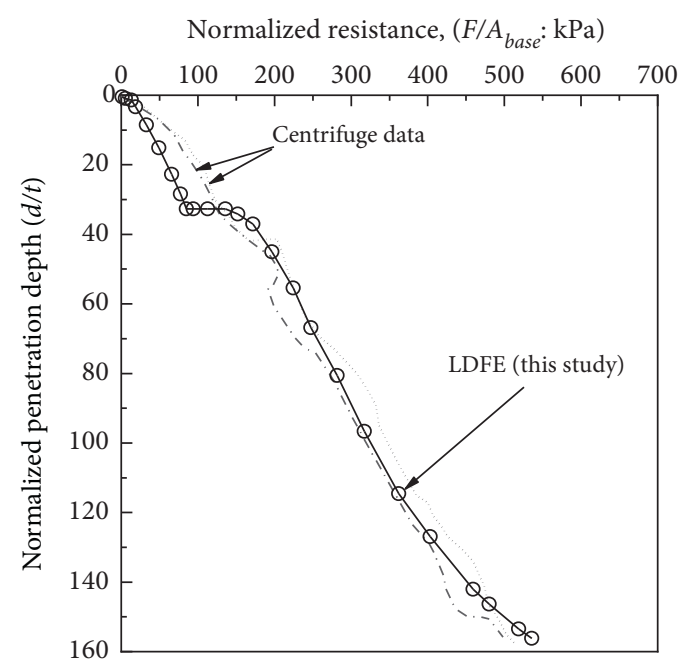

FIgURE 4: Validation in terms of resistance.
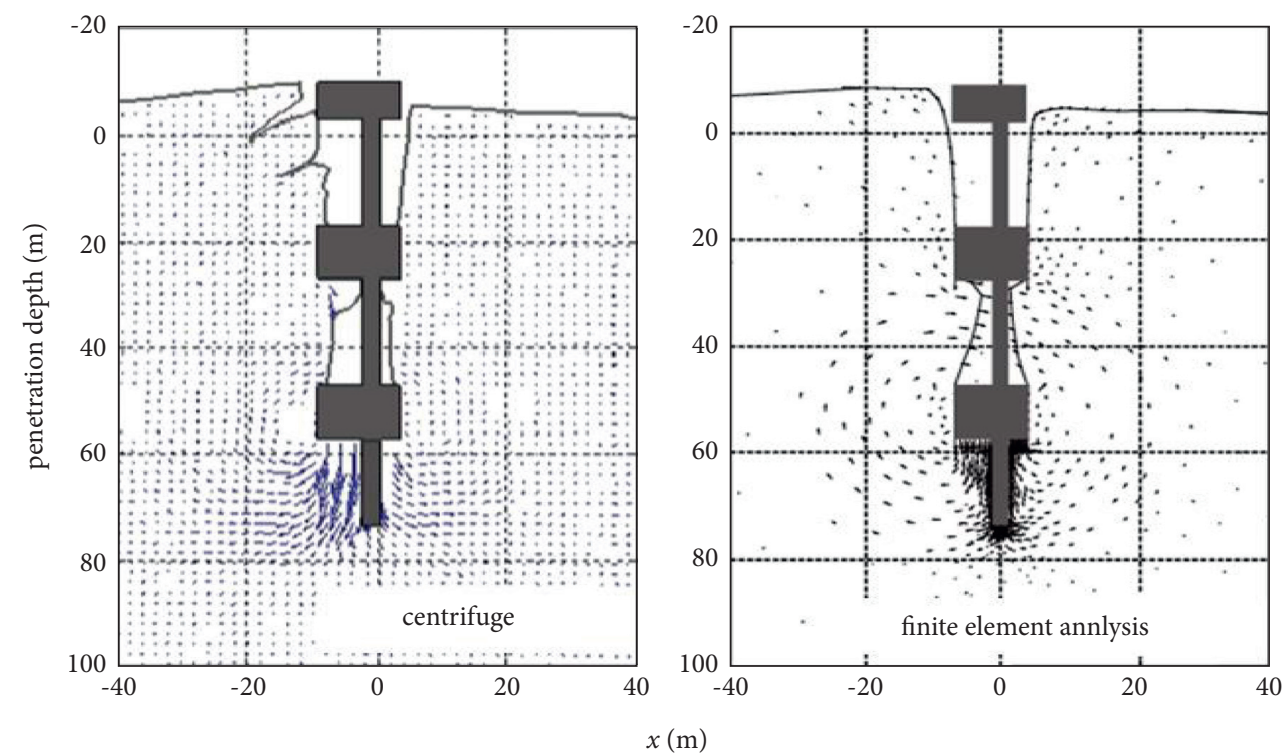

FIgURE 5: Validation in terms of soil movement.

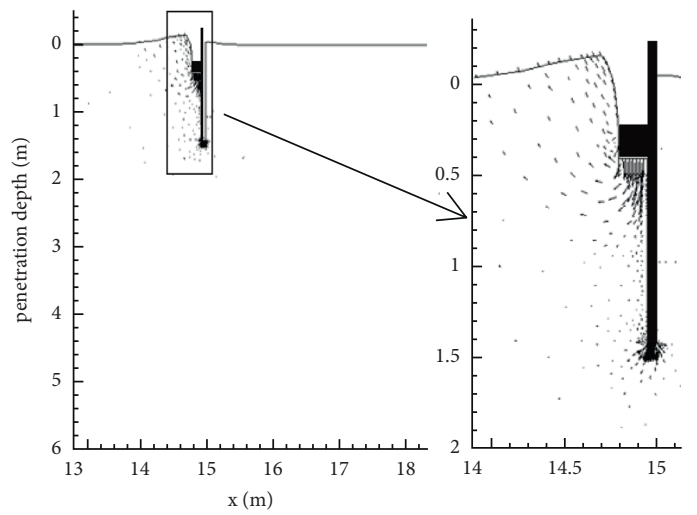

(a)

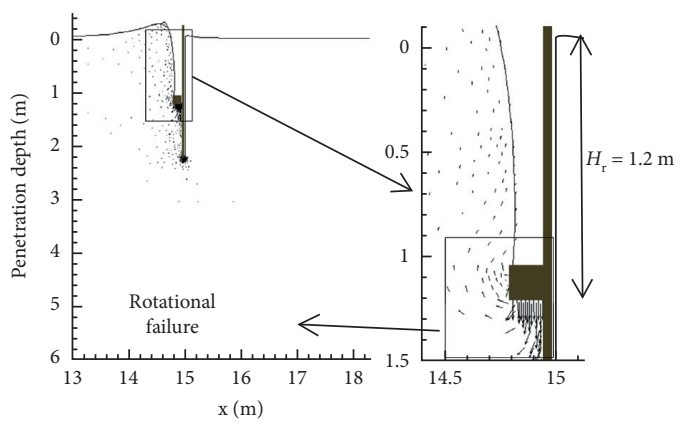

(b)

Figure 6: Continued. 


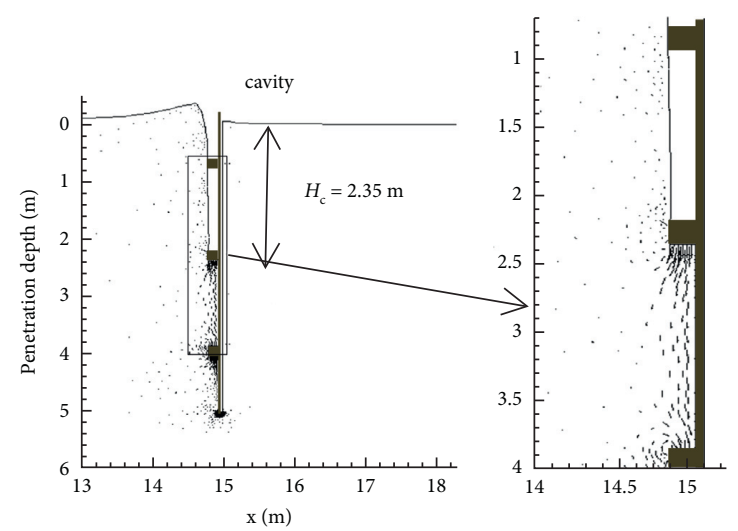

(c)

FIGURE 6: Soil movement of square stiffened caisson penetration.

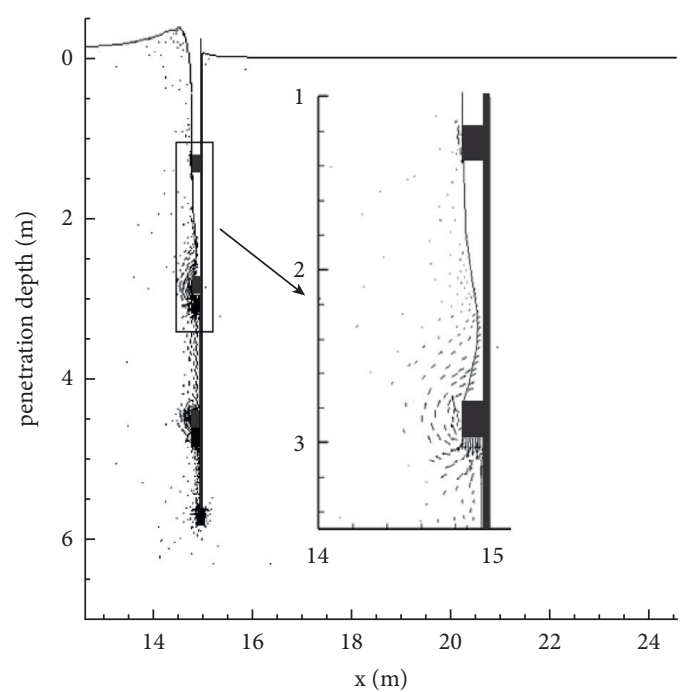

(a)

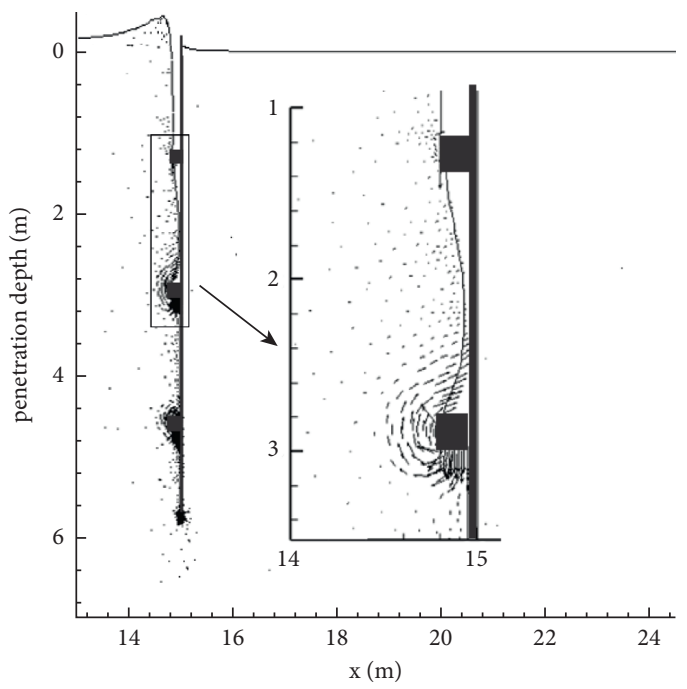

(b)

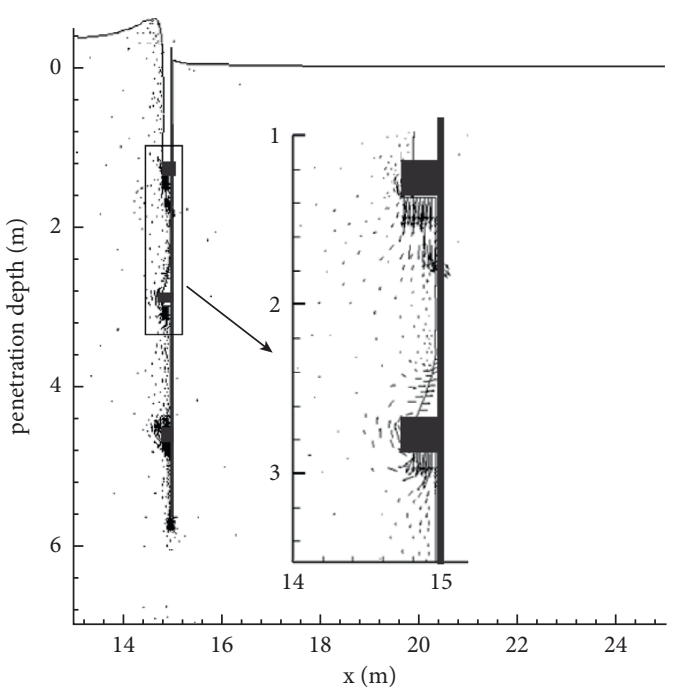

(c)

Figure 7: Effect of stiffener width on soil movement. (a) $b / t=2.0$. (b) $b / t=3.0$. (c) $b / t=5.0$. 


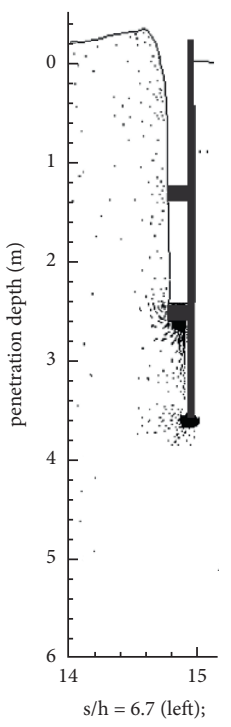

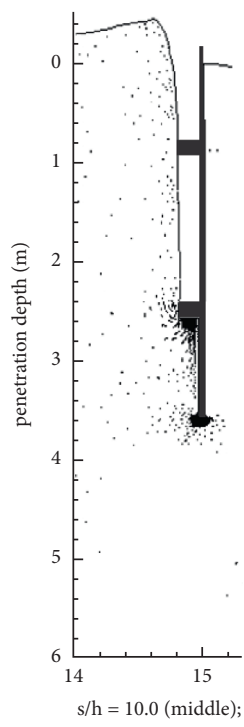

(a)
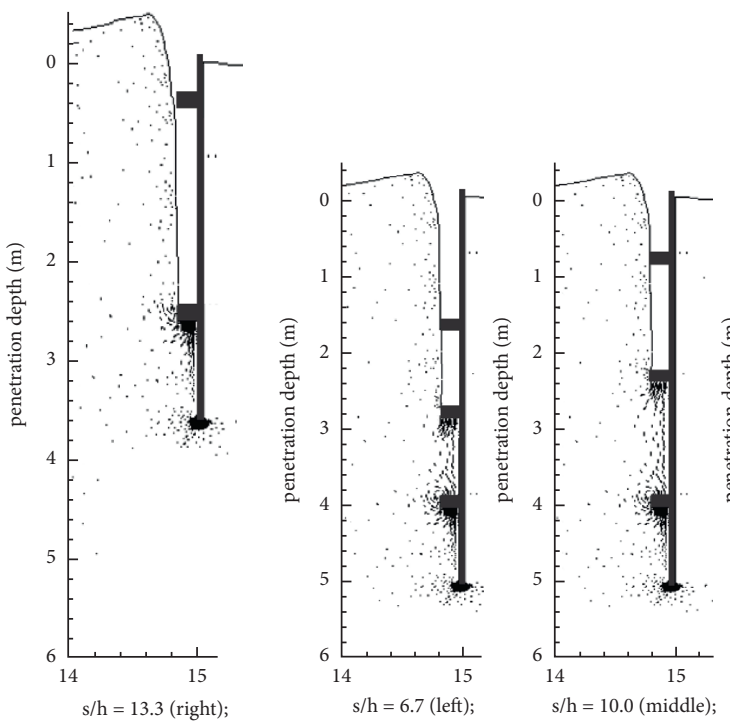

(b)

FIGURE 8: Effect of stiffener height and the distance of stiffeners on soil movement.

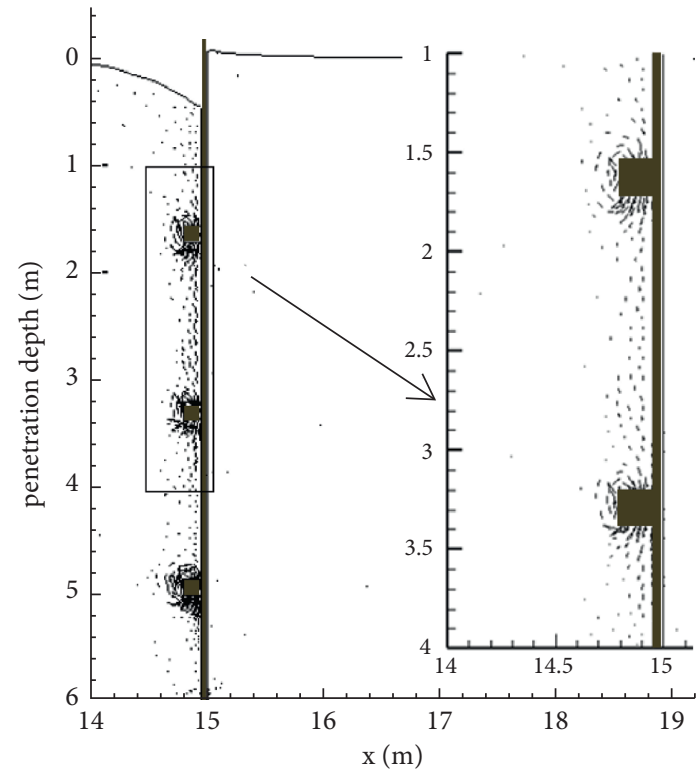

(a)

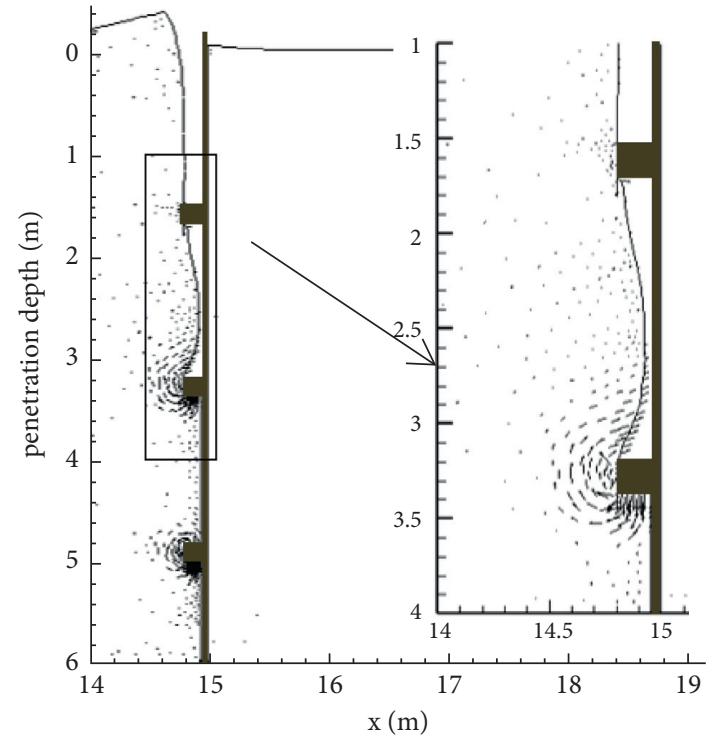

(b)

FIgure 9: Continued. 


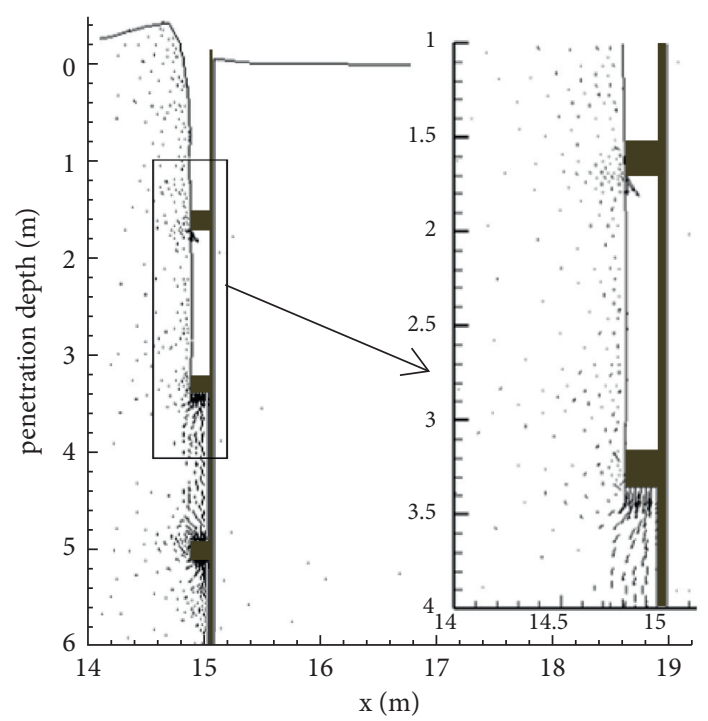

(c)

FIGURE 9: Effect of soil strength on soil movement. (a) $S_{\mathrm{um}} /\left(\gamma^{\prime}(b+t)\right)=0.42$. (b) $S_{\mathrm{um}} /\left(\gamma^{\prime}(b+t)\right)=4.2$. (c) $S_{\mathrm{um}} /\left(\gamma^{\prime}(b+t)\right)=8.3$.

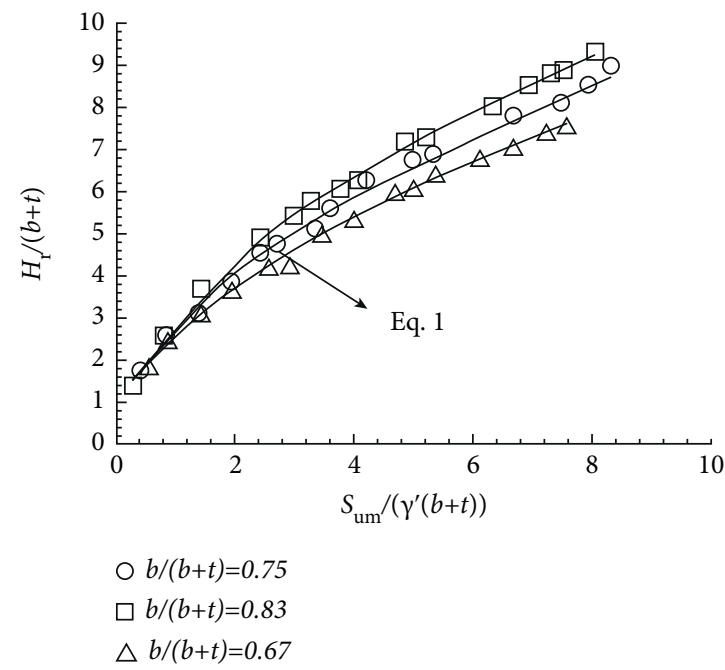

FIGURE 10: Design chart of the critical depth of rotational soil flow.

process of caisson penetration, the stiffener causes soil disturbance inside caisson, and the soft soil is trapped between the stiffeners and enters into the deeper soil layer along with the stiffeners, resulting in the lower soil strength around the caisson inner wall compared with the undisturbed soil at the same depth, which makes the internal and external friction calculations adapting the equivalent strength after the disturbance instead of the undisturbed soil strength when designing the caisson penetration resistance and subsequent bearing capacity.

\section{The Critical Depth Calculation}

Through the analysis of the effect of different normalized parameters on the soil flow mechanisms, the factors affecting the critical rotational flow depth $H_{\mathrm{r}}$ and the limiting cavity depth $H_{\mathrm{c}}$ include the stiffener width $b$ and the soil undrained shear strength (the soil surface undrained shear strength plays a main role).

To calculate and analyze a series of parameters in Group 8 in Table 1, fix $w=1 \mathrm{~m}, s=1.5 \mathrm{~m}, \alpha=0.2, t=0.05 \mathrm{~m}$, and $\gamma^{\prime}=6.0 \mathrm{kN} / \mathrm{m}^{3}$, change $S_{\mathrm{u}}$ and $b$, the quantification system of the critical rotational flow depth $H_{\mathrm{r}}$ and the limiting cavity depth $H_{c}$ when the stiffened caisson penetrates in the normally consolidated clay were obtained by a large number of parameter analysis, as shown in Figures 10 and 11. Hossain et al. also put forward the quantitative relationship diagram of the critical depth of spindle foundation for the investigation of spindle foundation penetrating into homogeneous clay. These studies show that the normalized critical depth increases with the increase of $S_{\mathrm{u}}$, which is consistent with the law obtained in this paper.

According to the above calculation of different parameters, the data relevant to the critical rotational flow depth 


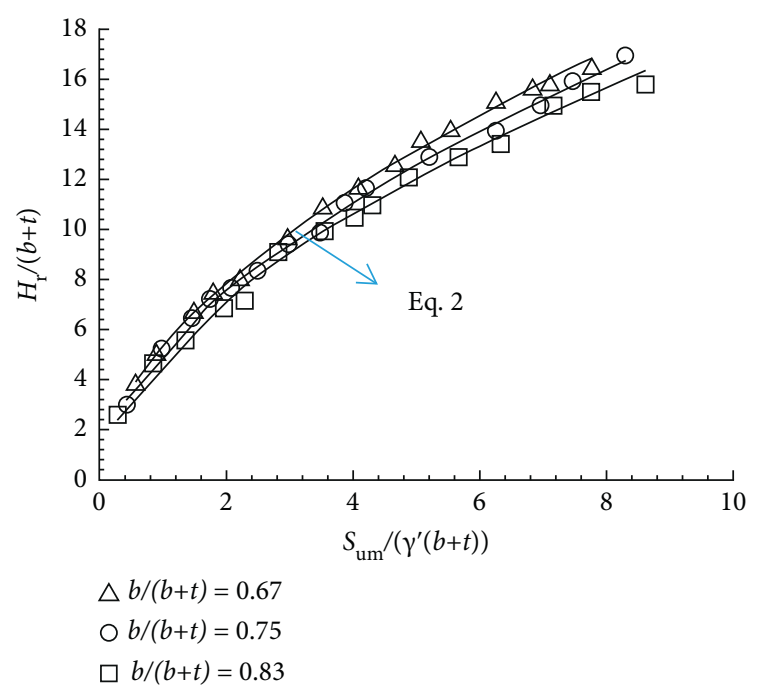

Figure 11: Design chart of the limiting cavity depth.

and the limiting cavity depth are obtained; from that, the following formula can be fitted $\left(R^{2} \approx 0.98\right)$ :

$$
\begin{aligned}
& \frac{H_{\mathrm{r}}}{(b+t)}=\left(0.68+2.80 \frac{b}{(b+t)}\right)\left(\frac{S_{\mathrm{um}}}{\left(\gamma^{\prime}(b+t)\right)}\right)^{0.54}, \\
& \frac{H_{\mathrm{c}}}{(b+t)}=\left(7.24+2.83 \frac{b}{(b+t)}\right)\left(\frac{S_{\mathrm{um}}}{\left(\gamma^{\prime}(b+t)\right)}\right)^{0.56},
\end{aligned}
$$

where $b+t$ usually ranges from $0.10 \mathrm{~m}$ to $0.35 \mathrm{~m}$.

\section{Concluding Remarks}

Soil failure mechanisms of the squared caisson penetrating in the normally consolidated clay has been studied undertaken throught the large deformation finite element analysis by using RITSS code in this study. with the aims of examining the effect of stiffeners on the behavior of failure mechanism os square stiffened caisson, and the findings can provide guidance for the design of square stiffened caisson. The following detailed conclusions were drawn:

(1) The critical depths of rotational flow $\left(H_{\mathrm{r}}\right)$ and the limiting cavity depth $\left(H_{\mathrm{c}}\right)$ were defined. When the penetration depth of bottom stiffener reaches $H_{\mathrm{r}}$, the soil starts to flow back into the bottom cavity, and when the soil heave height inside the caisson is higher than $H_{\mathcal{c}}$, there exist gaps between soil and structure, and soil does not flow back, that is, when the inner soil heave height is less than $H_{\mathfrak{c}}$, the soil flows into the cavity between the stiffeners with rotational soil failure mechanisms and is trapped, moving downwards together with the stiffeners and the skirt at the same velocity, and there is no relative slide between the pile and the soil and no friction. The internal and external friction calculations need to adapt the equivalent strength after the disturbance instead of the undisturbed soil strength.
(2) The factors affecting $H_{\mathrm{r}}$ and $H_{\mathrm{c}}$ obtained by the study and analysis of different parameters include the stiffener width $b$ and the soil surface undrained shear strength $S_{\text {um }}$; the corresponding design chart and equation of the critical depth of rotational soil flow and the limiting cavity depth were proposed; at the same time, the equation of predicting the maximum inner soil heave height was obtained. It shows that the cavity depth can be reached to $\sim 5 \mathrm{~m}$ for the case of stiff clay, which cannot be ignored for design.

(3) The interface coefficient $\alpha$, the stiffener width $h$, the stiffener spacing $s$, and the soil undrained shear strength gradient $k$ have minimal effect on $H_{\mathrm{r}}$ and $H_{\mathrm{c}}$, while the soil surface strength $S_{\mathrm{um}}$ has the largest effect, followed by the stiffener width.

(4) The softening and strain rate effects are not considering in this study, and it may conduct further study on it.

\section{Data Availability}

All data and FE results in the study are available from the corresponding author upon request.

\section{Conflicts of Interest}

The authors declare that there are no conflicts of interest regarding the publication of this article.

\section{Acknowledgments}

This study was supported by the Key-Area Research and Development Program of Guangdong Province (no. 2020B0101130009) and Guangdong Enterprise Key Laboratory for Urban Sensing, Monitoring and Early Warning (no. 2020B121202019). The authors also gratefully acknowledge the financial support provided by the Guangdong Basic and Applied Basic Research Foundation (2021A1515010828 and 2020A1515410001) and State Key Laboratory of Hydraulic Engineering Simulation and Safety of Tianjin University.

\section{References}

[1] K. H. Andersen, J. D. Murff, M. F. Randolph et al., "Suction anchors for deepwater applications," in Proceedings of the 1st International Symposium Frontiers In Offshore Geotechnics, pp. 3-30, ISFOG, Perth, Australia, September 2005.

[2] H. Dendani and J.-L. Colliat, "Girassol: design analysis and installation of suction anchors," in Proceedings of the Offshore Technology Conference, Houston, TX, USA, May 2002.

[3] C. Erbrich and P. Hefer, "Installation of the laminaria suction piles-a case history," in Proceedings of the Offshore Technology Conference, Houston, TX, USA, May 2002.

[4] H. Dendani, "Suction anchors: some critical aspects for their design and installation in clayey soils," in Proceedings of the Offshore Technology Conference, Article ID 15376, Houston, TX, USA, May 2003.

[5] M. S. Hossain, B. Lehane, Y. Hu, and Y. Gao, "Soil flow mechanisms around and between stiffeners of caissons during 
installation in clay," Canadian Geotechnical Journal, vol. 49, no. 4, pp. 442-459, 2012.

[6] K. H. Andersen, P. Jeanjean, D. Luger, and H. P. Jostad, "Centrifuge tests on installation of suction anchors in soft clay," Ocean Engineering, vol. 32, no. 7, pp. 845-863, 2005.

[7] H. Zhou and M. F. Randolph, "Large deformation analysis of suction caisson installation in clay," Canadian Geotechnical Journal, vol. 12, pp. 1344-1357, 2006.

[8] W. Chen and M. F. Randolph, "External radial stress changes and axial capacity for suction caissons in soft clay," Géotechnique, vol. 57, no. 6, pp. 499-511, 2007.

[9] Z. J. Westgate, L. Tapper, B. Lehane, and C. Gaudin, "Modelling the installation of stiffened caissons in overconsolidated clay," in Proceedings of the 28th Int. Conf. Ocean, Offshore and Arctic Engineering, Article ID 79125, Honolulu, HI, USA, January 2009.

[10] M. F. Randolph, M. P. O’Neil, D. P. Stewart, and C. Erbrich, "Performance of suction anchors in fine-grained calcareous soils," in Proceedings of the Offshore Technology Conference, Houston, TX, USA, May 1998.

[11] D. J. White, C. Gaudin, and N. Boylan, "Interpretation of T-bar penetrometer tests at shallow embedment and in very soft soils." Canadian Geotechnical Journal, vol. 47, no. 2, pp. 218-229, 2010.

[12] J. P. Carter and N. P. Balaam, AFENA Users' Manual, Centre for Geotechnical Research, Sydeny, Australia, 1995.

[13] M. S. Hossain, Y. Hu, M. F. Randolph, and D. J. White, "Limiting cavity depth for spudcan foundations penetrating clay," Géotechnique, vol. 55, no. 9, pp. 679-690, 2005.

[14] H. Ma, M. Zhou, Y. Hu, and M. Shazzad Hossain, "Interpretation of layer boundaries and shear strengths for soft-stiff-soft clays using CPT data: LDFE analyses," Journal of Geotechnical and Geoenvironmental Engineering, vol. 142, no. 1, Article ID 04015055, 2016.

[15] M. Zhou, M. S. Hossain, Y. Hu, and T. Zhang, "Numerical simulation of plug formation during casing installation of PCC piles," Canadian Geotechnical Journal, vol. 53, no. 7, pp. 1-17, 2016. 